I fear that the articles I have alluded to, have been written by one who is, perhaps, not dependent on the service, and can afford. in his easy chair, enjoying the "otium cum dignitate," to write complacently of the advantages of the service, and the brilliant prospects, present and future, held out $b_{J}$ it.

The author of these articles does not say, as he might, that a large proportion of assistant-surgeons get no cabins at all, and none such as their rank warrants. For does he show how inspectors of hospitals, as well as deputy-inspectors, have always held inferior rank to their brethren in the army; how our able and talented Medical Dirertors-General have been similarly treated; how unequally rank and prize-money are distributed amongst all classes of the medical corps, surgeons of thirty years' standing and npwards sharing in the latter with boatswains and carpenters. These and many other indignities might be shown, and it is only honest and fair to the student to do so, and not allow him to be inveigled into a service by too partial a representation.

It is for this purpose, Sir, I write, and I confess with a selfish object, as I an convinced that until the Admiralty are reduced to concession, by the impossibility of getting educated gentlemen to enter a service so degraded, they will never assimilate to that of his army brother the position of the

Portsmouth, Norember, 1858 . Naval SURgen.

\section{TREATMENT OF DIPHTHERIA.}

(XOTE FRON MONTAGLE IRAUYD, ESQ., M.R.C.S.)

$$
\text { To the Editor of TEE LANCE'. }
$$

SIP, - I have lately read with great interest several letters in your valuable journal on the subject of diphtheria, and having had considerable opportunities of watching the disease in all its phases, I beg to submit the result of the treatment I have universally adopted in upwards of sixty cases which I have attended during the last six months.

I quite agree with Mr. Stephens in believing the disease to be perfectly sui generis, and of an infectious and contagions character. The tonsils and soft palate are, for the most part, primarily affected, and I have found that lunar caustic freely applied to the diseased portion has had the effect of checking the progress of the malady. Bran-and-vinegar cataplasms constantly applied to the throat have been very beneficial. The internal treatment has been quinine with dilute nitric acid; and in some instances I have used a gargle of alum and dilute sulphuric acid with great advantage. The diet has been of the truly nutrient character-jellies, port-wine, \&c. In no case have I ventured to use any mercurial remedy, having seen the ill effects where such treatment has been adopted.

I have only lost one patient, and have had some very obstinate and severe cases. I believe it to be a disease of a purely adynamic character, requiring such treatment as $I$ have stated, and universally and successfully adopted.

I am, Sir, your obedient servant,

Strațton, Cornwall, Nov. 185s. InioNTAGUE BRAUND, M.R.C.S.

\section{HERTS MEDICAL REGISTRATION ASSO. CIATION.}

To the Editor of THE LAXCET.

Srr,--As yon were so good as to notice the formation of the Herts Medical Registration Association, in The LANCET, perhaps you will permit me to make a remark or two upon the objects of such societies, because they appear in some quarters to be mistnderstood. For instance, certain parts of this county having a readier access to the metropolis than to the county town of Hertford, some gentiemen have intimated their preference to join a similar society in London. Now, if the objects were the cultivation of literature or science, the metropolis would be, of course, the most suitable place for pursuing them. But the objects of these societies are very different. To render them of any service, they must be established in districts, both in the country and in the metropolis. If the Medical Act be expected todo any good, it is desirable to carry itout efficiently. It is doubtful whether there may not be many, even now, who are iguorant of the necessity of registering. These societies will open their eyes to such necessity. They will render assistance to the Registrar-General under the Council, so as to enable him to construct as perfect a register as the nature of things will permit. This can only be accomplished by the combination of qualified practitioners in different diutricts. These districts even should not be too large, otherwise the objects cannot be attained. The metropolis is capable of looking after itself.
These combinations will also impart a certain vitality to the profession. It is to be hoped that they will create a degree of esprit de corps, and do away with petty jealousies amongst the members of it, which are anything but creditable to our calling. They are calculated, moreover, to enable us to apply a degree of wholesome pressure upon the Council and Government, in case any further reform may be considered desirable. No such machinery existed before for any good or efficient purpose.

The Herts Medical Registration Association was established on the 1st of October, the day on which the Medical Act came into operation. As was stated in THE LANCET the following week, nearly one-third of the qualified practitioners residing in the county of Hertford invited to meet, gave their consent to it at the commencement. It now embraces amongst its members abont two-thirds of the county, and the number increases daily.

I merely state these facts as an inducement and encouragement for other counties, or other districus, to establish similar societies.

$$
\begin{aligned}
& \text { I am, Sir, your obedient servant, } \\
& \text { Hertford, Nov. } 18 \tilde{8} \text {. }
\end{aligned}
$$

\section{THE SCARBOROUGH SANATORIUM.}

\section{To the Editor of THE LANCET.}

Sm,--T have read, with no little surprise, your observations on marine sanatoria in the two last numbers of your most valuable publication, to which $I$ am an old subscriber, and to which we are all so much indebted for upholding the honour and dignity of the profession. I am the more astonished, because if Dr. Morley Rooke had had the candour to tell you how his statement had been met here, I am sure that your usual impartiality would have, at the least, made you demur until you had heard the other side-_"Audi alteram partem." I have no interest or prejudice in favour of one site more than another, but have some regard for truth and the interests of those for whom this charity is intended; and that he should say, "that the situation is at the foot of an almost perpendicular declivity, wherethere is a deficiency of air, imperfect solar light, and want of drainage," is so contrary to all truth, that I am astonished that any one with his eyes open could make such an assertion. The remarkable exception of Scarbro' from cholera during its repeated prevalence in these isles, is a striking illustration of the salubrity of this elimate; and it is matter of notoriety, that the more malignant diseases, or epidemic visitations, seldom or never prevail in the lower part of the town, which the older practitioners will testify to.

The choice of a site is all important-and no pains nor expense ought to be spared to secure the best; but when you consider the requirements, it is easier to find fault than to point out a better. You cannot have a sea-bathing infirmary everywhere, and there are some essentials which you cannot dispense with. You must have facilities for warm and cold bathing; you must have sea air; and last, not least, you must have shelter from the cold north and east winds, which prevail here in common with the whole east coast of England during the early spring months; for, however much you may deride the idea of an infirmury at the foot of a hill, the need of protection from cold for a large class of invalids is very imperative. The want of this at the Southport Sea-bathing Infirmary, when visited by a medieal friend a few weeks ago, was much complained of, and where there is no shelter at all. The purposed site is in the bosom of the southern bay, nearly on a level with the sands, on one side of the isthmus, gradually rising behind to the height of nearly two hundred feet, exposed to the sun the greater part of the day, and where there must always be a current of sea air across Irom one bay to the other, so that the atmosphere is thoroughly marine. I know of no other place in this neighbourhood where you can combine these requisites in such a degree.

When you state that the medical officers and others have protested against it, you must be under some mistake. Dr. M. Rooke is not attached to the infirmary in any medical capacity at all; but, as a small subscriber, was put on the building com. mittee, when, although he had no want of opportunity, he never once raised his voice against it, till deciding for the plans for building, two or three weeks ago, and for reasons best known to hinzself. He has shown the most uncharitable spirit, inasmuch as he, and one or two more, have taken every pains with a lady who has most liberally subscribed $£ 2000$, in order to get her to withdraw it, without effect. Twrelve of the medical gentlemen have expressed themselves in favour of the site, by signing a statement to that effect. 
But why the name Marine Sanatoria? I am never against improvement, but cannot see any advantage or necessity for the change from the old and intelligent one, "Sea-bathing Infirmary," so expressive and well understood by every one. I am sorry thus to encroach so much on your time, but the importance of the subject, in a sanitary point of view, will, I hope, be a sufficient apology. With every respect, I am, Sir, yours most truly,

Scarborough, Nov., 1858.

Alex. EASTON, L.R.C.S.E.

\section{MEDICAL REGISTRATION ASSOCIATIONS.}

\section{MEETING OF THE MEDICAL PROFESSION AT WREXHAM}

A MEETING of the medical practitioners of Wrexham and the surrounding neighbourhood (convened by circular) was held at the Wynnstay Arms Hotel, on the 16th inst., the following gentlemen being present :-T. T. Griffith, Esq., Dr. Edward Williams, Dr. Ed. Davies, W. Rowland, J. Dickenson, A. H. Churchill, J. Kenrick Lewis, E. Burman, and T. Eyton Jones, Esqrs., Wrexham; Dr. W. Williams, Mold; R. C. Roberts, and J. Ingman (Ruabon), Alfred Fleischmann (Gresford), Thos. Morris (Marford), Stephen Walmsley (Bangor), John Edmunds, (Chirk), Esqrs. Letters apologizing for absence were read from J. W. Moorhouse (Ellesmere), R. Parry Williams (Minera) Escrs. : and Dr. J. Williams, Mold. Communications were also received from Dr. Hughes (Mold), R. Roberts, sen., (Ruabon) and John Eyton (Overton), Esqrs. ; expressing their approval of the objects of the meeting, and requesting to be enrolled as members of the Association.

T. T. GRIFFITH, Esq., being unanimously called to the chair, explained to the meeting the objects for which they were assembled, and called upon Dr. E. WuLLrams to move the first resolution, which was seconded by J. K. LEwIs, Esq., viz. :"That it is expedient to form an Association for Wrexham and the surrounding district, consisting of legally-qualified practitioners, to aid the Registrar in carrying out the Registration Clause of the new Medical Act, and that it be entitled the - Medical Registration Association for Wrexham and its neigh. bourhood.'"

Proposed by J. Drckerson, Esq., and seconded by E. Burman, Esq., - "That a subscription be entered into, amounting to $2 \mathrm{~s}$. $6 \mathrm{~d}$. each member, to defray all necessary expenses."

Proposed by A. H. Churchis, Fso, and seconded by J. INGMAN, Esq.,_- "That it is desirable a committee should be formed, to carry out the above-mentioned object, consisting of all present, five to form a quorum, and a requisition signed by any three to be sufficient to call a meeting."

Proposed by R. C. PoberTs, Esq., and seconded by T. Morris, Esq.,_" "That a report of the proceedings be drawn up and forwarded to the medical journals.

Proposed by Dr. FDwD. WILIIAMs, and seconded by STEPHEN WALMSLEY, Esq.,_- "That T. T. Griffith, Esq., be president, and T. Eyton Jones, Fsq., honorary treasurer and secretary.'

Proposed by Dr. W. WILliams, and seconded by Dr. WDWARD DAVIES, - "That the thanks of the meeting be given to 'T. T. Griffith, Esq., for his able and impartial conduct in the chair." T. ExTon Jones, Hon. Treasurer and Secretary.

\section{STOCKPORT REGISTRATION ASSOCIATION}

A MEETING of the medical profession of Stockport and the surrounding district was held on the 2 nd inst., in the Boardroom of the Stockport Infirmary, for the purpose of forming a Registration Association for the neighbourhood, Dr. TURNER in the chair.

It was resolved,-1st. "That this meeting recognises the necessity of forming an Association to watch the registration under the new Medical Act.'

2nd. "That the gentlemen present (twenty-one in number) form the Association, with power to add to their number, to be called 'The Stockport Medical Registration Association.'

3rd. "That the business shall be transacted at general meet ings (five to be a quorum), to be called by the secretary, at the witten request of three members."

4th. "That Mr. Pitman be secretary and treasurer."

5 th. "That a subscription of $2 s .6 d$. each be entered into to defray expenses."

6th. "That a report be sent to the medical papers."

Dr. Turner having left the chair, a vote of thanks was passed to him by acclamation.

\section{COLLEGE OF DENTISTS OF ENGLAND.}

Ox Tuesday evening, Dr. RICHARDSOx delivered his thiri lecture on "The Medical History and Treatment of Diseases of the Teeth." The attendance was even larger than on the last occasion. The subject of the lecture was " Neuralyia in relintion to Toothache and Diseases of the Teeth." The lecturer commenced by describing the meaning of pain as a modification of sensation, and the relation which sensation holds to the brain, nerve, and blood. He then traced ont the ways by which that exaltation of sensibility of nerve known as neuralgia might be induced, and gave $a$ history of the symptoms of a neuralgic attack, with the modifications which sometimes occur, and the mode and cause of the cessation of the paroxysm. Next the pathological bearings of the disorder were briefly discussed, and then the causes. The causes the lecturer divided into four parts, (classifyins in these divisions the varieties of the malady) viz., General, Central, Local, and Reflex. Under the head general causes, there were included those forms of neuralgia which result from poisons, as malaria, and from poisons of diathesis, as the gonty diathesis. Under the second head, were considered those forms of neuralgia which result from mischief in some centre of the cerebro-spinal system, or from injury inrolving the trunk of a nerve between the affected part and the brain. In the third division, neuralgia, as dependent on a local irritation, was dwelt on; special reference being made to that form of the disease which results from deep-seated lesion of the teeth. The diagnosis in such cases was very carefully laid down. If it be found, argued Dr. Richardson, in any case that the neuralgia is confined to one side; if there be no distinct intermittence; if pressure on the nerve trunk relieve the paroxysm; if sedatives locally applied relieve the paroxysm, or if slight variations of heat or cold to the face induce the paroxysm, the evidence is pretty clear that the cause is local, and that a tooth is the local cause. In the last division, the lecturer described that class of cases in which neuralgia, and neuralgic toothache arise from disorder at a remote part, as from disorder of the stomach. The diagnostic points were here also carefully defined. Dr. Richardson concluded by explaining the special treatment adapted to each variety of nenralgia; bestowing most pains in the elucidation of those cases where the question of the propriety of tooth-extraction is brought forward, and condemning with great force the system of resorting, in any form of neuralgia, to violent depressive measures, pain being an indication in itself of depression, and of all depressants the one that is most effective.

\section{iteviral aldion.}

Royal College of Surgeons. - The following gentlemen, having undergone the necessary examinations for the Diploma, were admitted members of the College at a meeting of the Court of Examiners on the 19th inst.:-

ABLETT, EDwaRd, Southampton-street, Bloomsbury.

Browne, Cimarles Wirliam, Kew-green.

Callaway, Edward, Canterbury.

DREW, ALFRED, Fakenham, Norfolk.

Emmerson, Charles, Sandwich, Kent.

Hoptoy, George Ocravius, Judd-street, Brunswick-square. Marshate, John, Islington.

Punch, John Golden, Donoughmore, Co. Cork.

Thompsoy, Alexander Bea froy, Ballintra, Co. Donegal.

Watters, Henrey Buneury, Rathgar, Dublin.

The Fellowship.-The following members of the Royal College of Surgeons, having been elected Fellows at previous meetings of the Council, were admitted on the 18th inst., viz. :-

AlFord, STEPHex SHute, Haverstock-hill, diploma of mem. bership dated May 17, 1843 .

Bradley, Richard Hollayd, Trafalgar-road, Greenwich, April 12, 1843.

Bryart, WALter Johr, Bathurst-street, Sussex-square, February 17, 1843 .

Colniss, ChaMrers, Maryport, February 19, 1838.

Covltate, Wir. Milleer, Burnley, May 16, 1836.

Daniell, Willtam Fremanar, Army Staff, Nov. 5, 1841.

Deckworth, Johx Neisox, Acacia-road, St. John's-rood, Angust 27, 1839.

Eccles, A LFRED, Tunbridge Wells, April 12, 1843. 